\title{
16. The Public Service in the Aftermath of the Global Financial Crisis: Future-proof or future shock?
}

\author{
The Honourable Bill English
}

I wish to give a reasonably broad, high-level view of the way the New Zealand Government is currently thinking about public service, as well as to offer some of my own thoughts that are going to continue to influence us. The first point is that all organisations, public or otherwise, are dealing with a number of what are increasingly appearing to be permanent changes. I will highlight three here. The first is debt reduction in the developed world, which is a generation-long project. We really have no idea of what the ongoing dynamics of this are, because we have never done it before, and no-one else has done it under the circumstances the developed world currently faces. This makes constraint permanent.

Ubiquitous data and free information form a second, greater force. Traditionally, the power of government was as a holder and controller of information. That has gone. Not only can anyone (including nine-year-olds) now access information for free, they can do it immediately. Moreover, citizens no longer think governments should hold information as power over people in the way they used to accept.

A third feature I see as a permanent change is the ongoing shift of wealth, power and therefore influence from our traditional markets and allies to the Asia-Pacific region and other emerging economies.

In this context, the New Zealand and Australian public services are in a unique position to harvest ideas for change - a change that is inevitable. On the one side we have the developed world, which has begun and will continue to undergo for a couple of decades radical experimentation and crunching the costs of its public services. This process has only just begun; those who think the current debate is only about austerity are wrong, as debt levels are still rising across the developed world. All they are really doing in these countries (particularly the Eurozone) is shuffling around their balance sheets. The image I have in my mind is of staff in an emergency department standing around a bed discussing how much adrenalin to pump into an ailing patient. The approach they are taking is far from a cure.

And while on the one hand much of the developed world is going through radical experimentation, on the other hand the developing Asia-Pacific economies and other emerging economies want more consumption-led growth, 
and are therefore developing an appetite and a need for public services which they don't have. This makes us ideally positioned both to harvest the ideas from the more radical experiments from economies that are under more pressure than Australia and New Zealand and to on-sell our expertise on public service to emerging economies, who will want them. In such emerging economies there is scope for massive and rapid growth in the provision of effective public services.

We are entering an age of experimentation on a scale we haven't seen since World War II and its aftermath. What does the government of little old New Zealand think about this? Our approach is to try to create sufficient stability so as to get even more change. By this I mean that it is hard to make change in large, sophisticated organisations with customers who are sensitive to service levels when you are working from a short-term budget process. In such systems there is often confusion surrounding the divisions of responsibility, and a lack of focus on what you are trying to achieve.

Consequently, we have taken the opportunity over the past few years to make a number of changes that are part of what I call the 'responsibility model'. Under the responsibility model, organisations themselves - not treasury, not the minister of finance, not central agencies - are responsible for making change and delivering services within fiscal constraints. They are in the best position to do this, because they know best what they are doing. Politicians and central agencies often don't know, and their culture tends to be one of watching what's happening, compared with the people who actually have to do it. In other words, according to the responsibility model, your destiny is in your own hands and how you handle pressures is up to you - although of course we have a whole public service and it can provide support.

There are a number of features we put in place to try to create the sense of stability and responsibility that we believe leads to better long-term decisionmaking. The first is to avoid the temptation of rushing in and grabbing savings in an irrational and random manner, which is actually the long-term habit of treasuries. This is because treasuries have to meet a target, so they simply go and get the money - something that preoccupies everybody about their short-term survival and decision-making, and prevents them thinking about the longer term and the real fiscal drivers.

That, then, is my first point: focusing on the longer-term fiscal costs, accepting deficits in the shorter term with the view that if we think very hard about what we're doing, two, three or five years down the track we can actually be spinning out hundreds of millions of dollars of spare cash, not just the NZ\$20 million that is preoccupying us now. After all, the long-term focus works best when we know what we're trying to achieve.

There are a couple of critical aspects to this approach. One is that we are trying to get the strength of having targets without the weaknesses. The second is 
that our results are focused on communities and populations, not government departments. This is because people don't live in government departments. They don't measure the success of public services by the success of a government department; they measure it by looking around in their street and their suburb and the particular public service they happened to use yesterday. This pointrelating to where people are rather than where we are - is critical. For while the parliamentary accountability system is about tracking a dollar, not whether something works, we have to also keep track of the real world.

To focus on results, another thing we have done is break the annual budget cycle and move consciously to four-year budget plans. A recent survey of chief executives suggests that this is now leading to the right kind of conversations about the longer-term effects they are trying to achieve, and about the sectoral relationships they need across government to achieve those results.

Another factor we have been looking at is what I would call judgment not process. By this I mean that leadership in the public service should ultimately be about judgment, not about going through all the right processes. After all, as we move into a more adaptive environment, we don't have time for all the processes; we need people who are willing and able to quickly take a position and make a judgment in tough situations, rather than waiting around for the next budget cycle or whatever.

The changes we have put in place are starting to have some effect, and we have unashamedly taken a long-term view-longer than an electoral cycle and the life of one government. Ideally, government departments would not take part in our budget cycle, because they would have their own four-year revenue track and their own plan, allowing them to just go off and do it. We would simply keep an eye on them - something that would probably free up half of senior management's time, from what I can see.

That, then, is what we are trying to do to create stability. But what are the implications for the kind of change that is going to actually happen, not just at the macro level but also within public services? There are four I would like to propose.

The first is that the usual political boundaries don't apply anymore - not in New Zealand anyway, and not, I suspect, across the world. What do I mean by that? The other day I read one official's report, which kept referring to the political risks of a particular proposition. But it was wrong because it was based on what everyone used to talk about five years ago, but not today. I would argue the public today is much less susceptible to lobby groups and self-interest; the public today is much more interested in politicians and public servants just getting on with their jobs. They are much less worried about whether they were consulted, and they are not nearly as concerned about sacred cows. 
That doesn't mean that everything is up for grabs, but the sense of caution and risk management built into public servants from the time of plenty is now quite outdated. In fact, we are finding, as politicians, the only constraints on getting things done concern our own internal processes, not the public's attitudes or aversion to risk. The public is not marching in the streets against change, because they know change is necessary. They've been doing it in their homes, they've been doing it in their businesses. They think central government is just catching up with it, and they know local governments are about another two years behind, but that eventually they will get there.

In that context, the public is very focused on the economy. They want their public service to work well-they actually expect that - but they also want their public service to focus on growth. And I know this is a radical idea for some, but as we write our regulations and our policies we need to know that the people to whom we are applying them - who actually pay for us - have as their top priorities: one, job security; two, a job for their teenager; and three, a bit more income, so they can increase their savings and pay off their debt. Everything else comes after that. We have quite some way to go for that strong focus on economic opportunity to filter right into every corner of the New Zealand Public Service.

The whole world is headed in this direction. I have been in discussions in the past year where countries like Canada and Japan, whose governments of all political persuasions have been for generations opposed to free trade, are starting to advocate free trade. Why? Because they need a growth story for the middle class, and there's nothing much else around that is working. Our public in Australia and New Zealand is where the public of most of the developed world is right now - that is, they know the world has changed, they expect us to behave in different ways that reflect their much deeper sense of economic insecurity in doing what we can to reinforce a sense of security.

The second implication of the changes that are occurring is that policy is now a commodity. My twelve-year-old son can print off world 'best practice' policy from the OECD website in 10 minutes flat if you asked him to. He doesn't need a degree, he doesn't need highly trained policy thinking; he can get this kind of information now from anywhere for free. What matters now is not the ability to sit around and think about high-level policy; what matters now is a detailed understanding of how policy applies to a particular setting and how to make it work. Our public services in Australia and New Zealand have some way to go to realise this. They need to ask themselves the question: why would someone pick the best thing to do? This process is often largely accidental in the public service at the moment.

Why would public servants get out of bed in the morning and try really hard to make something work? How do they tell whether it's working, and if we found 
out it wasn't working, would we do anything about it? The answer to that last question has traditionally been no. Instead, we go and find another good idea and put it on top of the one that's not working, and if that doesn't work, we go and find another one. The result is that over 30 years we accumulate a very expensive failure. After all, if we're going to fail, let's do it at low cost. Policy, then, is a commodity, and the critical knowledge that has to be built in our public services should be centred on the institutional arrangements that are going to make policy work. The public is not going to tolerate us spending money on stuff that doesn't work; five years ago they would have, now they don't, and what's more our lenders are not going to lend us money for stuff that doesn't work.

So if we want to maintain service levels for the public, we must flush out what doesn't work, and often that requires a change in our institutional incentives, and some basic institutional economics. To do this we need to determine what incentives people face and what signals are out in our public service market to tell people how to behave. We need to better understand the institutional arrangements that are about success, and this has become a current focus of the New Zealand Government.

A third implication of this world we are going to change is that other people can help us. In New Zealand and to some extent in Australia, we have had a period where the political climate discouraged any further privatisation. Until 2008 we had a Labour government in New Zealand which put a huge premium on who did the job. Their view was that the public service had to do it, because they are apparently the only ones who care, and those other nasty people who are not in the public service are going to rip you off, make excessive profits and not care about anything. By taking this approach, the Government cut itself off from a vast pool of knowledge, particularly knowledge about something that everyone is coming to understand now: how to manage risk.

In the public service over the past 20 years, risk has effectively meant avoiding embarrassing media stories. In the next 20 years, by contrast, it will mean whether you can manage the operational and financial risks of the vast expenditure and the vast capital expenditure that we control. But we don't have those skills: governments are terrible at managing assets. Given that there are people out there who have spent billions of dollars building up investment and the intellectual property of managing assets, why don't we use some of their knowledge?

Similarly, we don't know much about how social programs impact on communities, or whether much of what we do undermines the natural collectivism of the nongovernmental community. Consequently, we better work with those people who do understand it. After all, while they don't have public policy degrees and are not paid a lot, they do know a lot about the places in which they live and how the dynamics of those places work, and we need to see them as equal partners. 
In New Zealand, we have had a fantastic little experiment in this recently with something called the 'Social Sector Trials'. The idea is simple: we go to six small towns with problems with youth and find someone-essentially anyone who will turn up - and tell them that they control the government spending related to the services supporting youth; they make the decisions. In mid 2012, after just 12 months of this experiment, we had a presentation to cabinet of these young people from small provincial towns - none with a population of more than 10000 - telling us what they had achieved with about NZ\$100 000 and some control over other government spending. It was fantastic.

The presenters had a fully blended grip of all the public policy issues associated with the financing, delivery and effectiveness of services for quite a difficult part of the community. They gave exemplary presentations and descriptions of what they were doing. This kind of capacity is everywhere, and public services have to learn how to use it, because most of our approaches don't work when we ignore that capacity in communities and in families. Outsiders can help us, and in fact unless you are working with other people, you probably have it wrong.

If, as a public servant, you are still living in a bubble where you believe 'the public service cares and they are the only ones who know what they are doing', you are wrong, because I haven't come across a single example in the past three and a half years where that's the correct diagnosis of the situation. I have come across many examples where by reaching out, viewing society as a network not a hierarchy and acknowledging that other people know stuff we don't know, we have been able to make fantastic advances in the quality and the economy of our services.

And this of course leads to a different kind of leadership. We are in the same situation as much of the private sector, although we can't move as quickly to change it, where a lot of our skill sets come from the time of plenty. How to get in the minister's office door, how to crank out more cash, how to manoeuvre the strategy out there-all these skills are now redundant. Such approaches may have been applicable at the time, but that is no longer the case. Instead, the kind of leadership we particularly need is the kind of leadership that allows disruptive talent to emerge, and by this I don't mean chaos.

I mean, instead, that we are after leaders who, in spite of pressures associated with the financial squeeze, can have fresh analyses, think laterally and have a different set of relationships than were previously needed to succeed in an organisation.

If we rely only on incremental adaptation then changing technology and increasing public demand are going to squeeze our capacity, push the anxiety levels through the roof and the morale through the floor so that in the end 
someone else will have to come in and do the job. There are a lot of other aspects of leadership that are very important in the public sector; it involves quite specialised skills, but is easily disparaged by those outside the public sector. The people who come in, however, find it's a good deal more complex. The public service is not a business, but we must have room for disruptive talent.

In New Zealand across the board, we are implementing a range of significant changes: our defence forces are going through probably the biggest reorganisation of any defence force in the developed world; we're making significant changes to our law and order system, which means we're closing prisons for the first time in a generation; we're looking at welfare reform, which has aspects that are quite unique, and are already changing our thinking about our welfare population. In addition to these changes we have another massive challenge that we haven't made much progress on yet: the affordability of social housing - the Government's single biggest asset. We are also attempting to change the way we deal with information and privacy, and we expect to make some real progress in these fields over the next three or four years.

The reason we have been able to get as far as we have without significant disruption, and the reason we have confidence we can get quite a long way further, is that we think most of the talent we need in our public service is already there - it just needs to be given a clearer sense of direction. To do this we need to nurture a culture that allows different talent to come to the fore.

A good illustration of this was demonstrated following the 2011 Christchurch earthquake. In the first week after the disaster, I got to see New Zealand's public service adapt to a high-stress situation that demanded rapid action across a number of issues that were not simply complex, but also of a nature we had not dealt with before. A small group of people did a magnificent job of this in the early stages, and that level of excellence has been maintained.

We are fortunate in New Zealand to be able to undertake our own radical experiments; it is a place where you can break all the rules. And I hope that much of what I have covered in this chapter will serve as lessons for what you should do when you're allowed to break all the rules. We hope to harvest the product of that experiment and spread it across our public service, because we think that's the only way we are going to be able to achieve better public services when we have less resources to do it with. 
This text taken from Future-Proofing the State: Managing Risks, Responding to Crises and Building Resilience, edited by Jonathan Boston, John Wanna, Vic Lipski and Justin Pritchard, published May 2014 by ANU Press, The Australian National University, Canberra, Australia. 